\title{
Tim Prodi Kalk PIP Semarang Membantu FGD AMY dalam Rangka Pengabdian Kepada Masyarakat
}

\author{
Winarno \\ Politeknik Ilmu Pelayaran (PIP) Semarang \\ Email:winarno@pip-semarang.ac.id
}

\begin{abstract}
Abstrak
Politeknik Ilmu Pelayaran (PIP) Semarang menugaskan the team of KALK untuk membantu Focus Group Discussion (FGD) di Akademi Maritim Yogyakarta (AMY) dalam rangka pelaksanaan pengabdian kepada masyarakat. Penugasan ini didasarkan pada surat permintaan dari Direktur AMY kepada Direktur PIP Semarang untuk mengirimkan narasumber ahli dari dosen Prodi Ketatalaksanaan Angkutan Laut dan Kepelabuhan (KALK) untuk membantu memberikan panduan serta pengalaman pada acara FGD prodi Ketatalaksanaan Pelayaran Niaga (KPN) di AMY. Bahwa AMY sedianya akan melaksanakan peninjauan ulang serta re-design terhadap kurikulum prodi KPN yang dimiliki agar sesuai dengan kebutuhan industry atau bahasa populernya adalah link and match.
\end{abstract}

Kata Kunci: Focus group discussion, Pengabdian, Masyarakat

\begin{abstract}
Semarang Merchant Marine Polytechnic (PIP) assigned the study program of Sea Transportation and Port Management (KALK) to assist in Focus Group Discussion (FGD) at the Maritime Academy of Yogyakarta (AMY) in the framework of implementing community service. This assignment was based on a letter of request from the Director of AMY to the Director of PIP Semarang to send expert speakers from KALK to help provide the guidance and experience on the FGD of Commercial Shipping (KPN) Study Program in AMY. AMY is supposed to carry out a review and re-design of the KPN study curriculum that is owned to suit the needs of the industry or as known as "link and match"
\end{abstract}

Keywords: Focus group discussion, Community Service

\section{PENDAHULUAN}

Politeknik Ilmu Pelayaran (PIP) Semarang menugaskan Tim Prodi KALK untuk membantu Focus Group Discussion (FGD) dalam melaksanakan peninjauan ulang serta re-desain terhadap kurikulum Prodi KPN yang dimiliki agar sesuai dengan kebutuhan industri atau bahasa populernya adalah link and match di Akademi Maritim Yogyakarta (AMY) dalam rangka pelaksanaan pengabdian kepada masyarakat. Untuk merespon surat permintaan tersebut kemudian Direktur PIP Semarang Capt. Dr. H. Wisnu Handoko,
M.Sc menugaskan salah satu Dosen yaitu Dr. Winarno, M.H selaku Kaprodi KALK PIP Semarang yang didampingi Andi Prasetiawan, S,SiT., M.M untuk memenuhi permintaan tersebut. Hal itu didasari bahwa Prodi KALK PIP Semarang sudah terlebih dahulu dan mempunyai pengalaman dalam melaksanakan peninjauan dan re-desain kurikulumnya sepanjang tahun 2016 serta sebagai anggota tim pembahas Peraturan Kepala Badan Pengambangan SDM Perhubungan No. PK. 07/BPSDMP-2016 Tentang Kurikulum Program Pendidikan dan Pelatihan Pembentukan dan Peningkatan Kompetensi di Bidang 
Pelayaran, yang juga didahului dengan menggelar FGD terlebih dahulu pada tanggal 18 September 2015 yang menghadirkan banyak pemangku kepentingan maupun pengguna jasa lulusan Prodi KALK PIP Semarang sebagai syarat untuk mencari keterhubungan antara kurikulum dengan kebutuhan industri pelayaran.

\section{METODE}

FGD di AMY dilaksanakan pada hari Sabtu tanggal 18 Februari 2017 mulai dari jam 08.00 s/d jam 16.30 WIB yang dilaksanakan di kampus AMY jalan Magelang Yogyakarta. Hadir dalam FGD tersebut adalah Direktur AMY, para Wakil Direktur, seluruh Dosen Prodi KPN, perwakilan Dosen Nautika dan Teknika, dan yang tidak kalah penting adalah kehadiran para pengguna jasa lulusan Prodi KPN yang sebagian besar adalah alumni AMY serta sekaligus mewakili instansi masing-masing baik dari perusahaan pelayaran, pengusaha, maupun aparat pemerintahan dari Kantor Syahbandar dan Otorita Pelabuhan (KSOP). Kegiatan dimulai dengan paparan dari Direktur AMY dengan menyampaikan apa yang dikehendaki oleh pihak AMY agar Prodi KPN dapat merespon permintaan industri pelayaran terhadap lulusannya sehingga otomatis kurikulum yang ada saat ini harus menyesuaikan dan didasarkan pada kebutuhan jabatan dalam industri pelayaran yang ada saat ini. Berawal dari keprihatinan tentang kurang siapnya para lulusan dalam merespon kebutuhan pasar kerja industri pelayaran saat ini dan rupanya hal ini hamper terjadi pada sebagian besar lulusan Prodi sejenis.

\section{HASIL DAN PEMBAHASAN}

Dr. Winarno, M.H sebagai nara sumber utama pada FGD ini kemudian memaparkan latar belakang terjadinya peninjauan ulang dan re-desain terhadap kurikulum Prodi KALK pada Perguruan Tinggi Pelayaran di lingkungan Badan Pengembangan SDM Perhubungan
Kementerian Perhubungan RI, dimulai dari pelaksanaan FGD serupa yang berfungsi untuk mengumpulkan informasi dan masukan serta identifikasi kurikulum yang diharapkan sesuai dengan kebutuhan industri pelayaran terkini apalagi pada era Masyarakat Ekonomi Asean (MEA/AEC) yang tidak bisa tidak lulusan Prodi ini harus kompeten dan responsif dengan kebutuhan pasar kerja industri pelayaran terkini baik di nasional maupun internasional pada regional ASEAN. Dipaparkan pula bagaimana proses pengayaan materi yaitu TIM Prodi KALK PIP Semarang melaksanakan road show atau berkeliling dan berkunjung melakukan studi banding terhadap perusahaan pelayaran baik swasta/BUMN, terminal petikemas terbesar di Indonesia yang ada di JICT (Jakarta International Container Terminal), Green Port Terminal PT. Terminal Teluk Lamong di Surabaya, Terminal Peti Kemas Semarang sampai pada waktu meninjau fasilitas crane simulator di Kongsberg Singapura dan Integrated Simulation Centre of Singapore di Singapore Maritime Academy. Bagaimana Tim Prodi KALK PIP Semarang ikut membahas cikal bakal terbitnya PK. 07/BPSDMP-2016 yang membagi Prodi KALK menjadi tiga konsentrasi pilihan yaitu Terminal Petikemas, Terminal Konvensional, dan Bisnis Pelayaran. Termasuk bagaimana proses penamaan ulang mata kuliah pada tiap-tiap konsentrasinya yang disesuaikan dengan bidang pekerjaan dan jabatan yang ada di industri pelayaran. Serta disampaikan pula mekanisme di luar lembaga pendidikan induk dalam mensiasati kebutuhan lulusan yang profesional yaitu melalui Lembaga Sertifikasi Profesi (LSP) Pihak I yang sudah dimiliki PIP Semarang.

Peserta FGD yang berjumlah 30 orang menyimak dengan antusias terbukti dengan banyaknya pertanyaan yang disampaikan pada sesi tanya jawab, hampir semua peserta baik dari Dosen AMY maupun dari alumni bertanya berbagai hal yang terkait kurikulum dan prospek lulusan Prodi KPN, dan semua pertanyaan dijawab dengan memuaskan karena memang diskusi dan 
jawaban berdasarkan pengalaman yang sudah dilaksanakan tim Prodi KALK PIP Semarang. Kemudian pada sesi penyusunan kurikulum terjadi diskusi yang dinamis dan terarah karena sudah disampaikan panduan dan garis besarnya oleh Tim Prodi KALK PIP Semarang dengan banyak usulan yang mengarah atau memodifikasi panduan kurikulum operasional yang dimiliki Prodi KALK PIP Semarang dan berpedoman pada PK. 07/BPSDMP-2016.

Pada akhir sesi dibacakan hasil diskusi tentang usulan kurikulum baru Prodi KPN AMY yang disampaikan oleh KaProdi KPN AMY yang kemudian menjadi catatan adalah perlu diadakan penyempurnaan hasil pembahasan kurikulum ini dengan melaksanakan studi banding ke beberapa

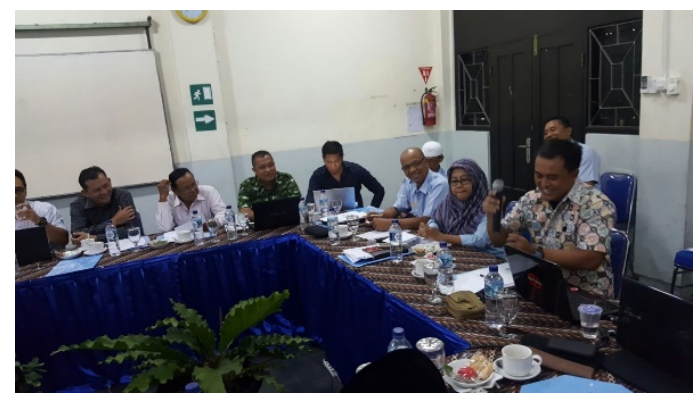

instansi dan industri pelayaran yang menjadi rujukan serta mengundang nara sumber dari industri pelayaran sebagai pengayaan materi seperti yang dilakukan Tim Prodi KALK PIP Semarang. Hal itu dibutuhkan komitmen yang tinggi dari para penentu kebijakan di AMY maupun para Dosen Prodi KPN yang tentu saja akan menguras tenaga dan pikiran serta biaya yang tidak sedikit, tetapi hal itu mutlak dilaksanakan agar tercapai sasaran yaitu terbentuknya kurikulum Prodi KPN AMY yang sesuai dengan kebutuhan industri pelayaran terkini baik nasional maupun internasional.

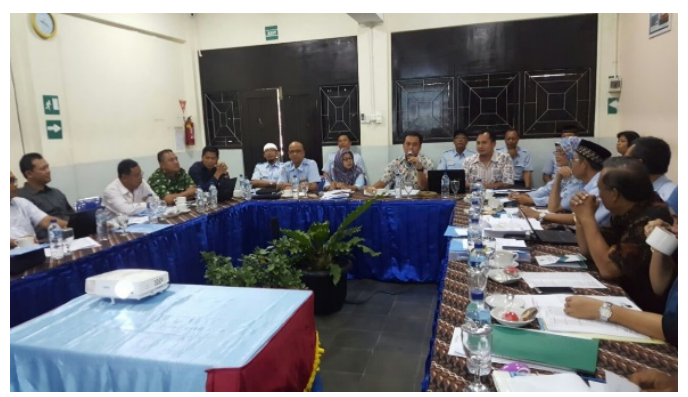

Gambar 1 . Kegiatan FGD

\section{SIMPULAN}

Perlu diadakan penyempurnaan hasil pembahasan kurikulum ini dengan melaksanakan studi banding ke beberapa instansi dan industri pelayaran yang menjadi rujukan serta mengundang nara sumber dari industri pelayaran sebagai pengayaan materi seperti yang dilakukan Tim Prodi KALK PIP Semarang. Hal itu dibutuhkan komitmen yang tinggi dari para penentu kebijakan di AMY maupun para Dosen Prodi KPN yang tentu saja akan menguras tenaga dan pikiran serta biaya yang tidak sedikit, tetapi hal itu mutlak dilaksanakan agar tercapai sasaran yaitu terbentuknya kurikulum Prodi KPN AMY yang sesuai dengan kebutuhan industri pelayaran terkini baik nasional maupun internasional. 
